\title{
Ricardo Palma y la Guerra con Chile (1879-1883)
}

\author{
Por Sandro Chiri Jaime
}


Doctor en Literatura Hispanoamericana por la Temple Univesity (USA) y licenciado en Literatura en la Universidad de San Marcos. Director del Equipo de Investigación y Producción Literaria de la Casa de la Literatura Peruana. Dirigió la revista "La casa de Cartón”. Es docente en las universidades de Esán, San Ignacio de Loyola y Antonio Ruíz de Montoya. 
La brevísima producción textual de Palma sobre la Guerra del Pacífico lleva el sello indeleble del testigo de una época atroz, la huella del dolor de haber sido víctima de los funestos acontecimientos y la patriótica intención de encomiar el esfuerzo y el valor de los que entregaron sus vidas por la defensa del Perú. No se descarte entonces el fuego de la pasión, por más breve que sea el relato, en las historias que emite un narrador que acota, aclara y se entromete a favor de la causa peruana.

La bonanza, el boato y el brillo de la economía del Perú acaso hayan sido la razón fundamental por la que las fuerzas chilenas -estimuladas por el capital inglés- codiciaron denodadamente territorio peruano. Bonanza que tuvo como base la exportación del guano tanto a los Estados Unidos como a Inglaterra.

La denominada era del guano coincide con los años previos a la mencionada guerra. Peter Klarén entiende que durante toda esa época -que va de 1840 a 1880- "el estado peruano captó entre el sesenta y setenta por ciento de las rentas derivadas de este producto" (Klarén 214). Es decir, "el guano fue convertido en un monopolio estatal siguiendo una inclinación colonial por el mercantilismo y el estatismo" (Klarén 214). La economía peruana, entonces, se sustentó durante aquellas décadas del XIX en la venta del excremento de las aves que servían de abono a tierras europeas y norteamericanas, con "un alto contenido de fosfato como propiedad que oxigena la tierra e incrementa su producción."

I Ver Alex Murazzo. "La prosperidad falaz" (2007). 
El mismo historiador norteamericano arguye que el "Perú alcanzó la cima de su paso -inducido por el guano- de mendigo a millonario en la década de 1850 y comienzos de la de 1860, bajo la égida del triunfante liberalismo exportador y la mano dura de Castilla" (Klarén 215). Sin embargo, ese auge "guanero de mediados de siglo [XIX] llevó a una profunda división de larga duración entre la costa modernizante y la sierra económicamente atrasada" (Klarén 211). Y en cuanto a la vida cívica de la mayoría, Novoa sostiene que en el Perú, entre 1860 y 1900, las condiciones de alfabetismo, educación, trabajo remunerado en dinero y contribuciones al erario público, exigidas para el ejercicio de los derechos políticos, podrían encontrarse exclusivamente en las ciudades. En consecuencia los ciudadanos activos de la constitución de 1860 , los republicanos de la sociedad Independencia Electoral, o bien los propietarios instruidos en sus derechos fundamentales, estuvieron circunscritos a la esfera urbana, y acaso costeña (Novoa 283).

Pero no solo eso: el festín sustentado únicamente en el monopolio costeño y en la exportación del guano originó, asimismo, una prosperidad falaz, tal como lo sugiere reiterativamente Basadre (1969), en tanto que tarde o temprano se originaría un "agotamiento de los depósitos del guano y el estallido de la Guerra del Pacífico" (Klarén 231). En el ínterin, sin embargo, hubo un esplendor tan inusitado que la capital del Perú se transformó físicamente en una metrópoli 'europeizada', chic pero sobrepoblada. Los grandiosos bulevares de Lima estaban ocupados por suntuosas mansiones, elegantes parques y nuevos e imponentes edificios públicos. Las fortunas familiares se incrementaban y las filas de la plutocracia crecían al mismo ritmo, no solamente con las ganancias de los comerciantes, que casi se triplicaron después de 1845, sino también con el regalo de veinticinco millones de dólares de la 'consolidación' estatal. 
Los limeños emergentes, culturalmente orientados a Europa, lucían las últimas modas continentales y consumían añejos vinos franceses entre toda la amplia gama de bienes importados disponibles, valorizados en más de quince millones de dólares para 1860. Al igual que toda elite, esta liberalidad de la riqueza llevó a ocasionales orgías de exhibición pública y consumo conspicuo. Tal fue el caso del célebre baile realizado en Lima en 1873, en el cual los finos vestidos y joyas de cada dama habían sido importados de Europa especialmente para la ocasión, a un costo de diez mil a cincuenta mil soles cada uno. [...] El atractivo del 'boom' guanero peruano también actuó como un imán para la inmigración extranjera al Perú (Klarén 216).

Esta visión fastuosa de la patria, previa a la Guerra con Chile, se expone con meridiana claridad en más de una tradición palmista, donde la imagen esplendorosa de la capital peruana se vislumbra con lujos de detalles; a pesar de que a los viajeros franceses que visitaron el Perú entre 1860 y 1874, les llamó particularmente la atención una ciudad como Lima a la que llamaron "la babel del siglo XIX, pues la multitud de mezclas raciales los desorientaba y disgustaba, tal como la variedad de lenguajes confundía a los habitantes de la ciudad bíblica" (Cosamalón 160).

En efecto, no solo el Perú multiétnico deambulaba por la próspera urbe, sino también viajeros llegados del Viejo Continente. Por ejemplo, en la tradición "Entre Garibaldi... y yo" se muestra a un próspero mercader europeo avecindado en el Perú, tal el caso de "don Antonio Malagrida, acaudalado comerciante italiano de esa época y en cuya casa, de reciente construcción, tenía por huésped a Garibaldi los días en que este venía al Callao [...]. La casa de Malagrida fue la que forma el ángulo de las calles de Palacio y Polvos Azules, con grandes almacenes en la parte baja" (TP1968, 1124). Esa lujosa arquitectura ubicada 
frente al palacio presidencial no es más que una leve muestra del esplendor guanero y del auge económico de Lima.

La tradición "El baile de la victoria," asimismo, puede ser percibida acaso como una evidencia harto ejemplar del boato limeño. Acá, Don Bernardo, refinado joyero alemán, almacena verdadera fortuna en Lima vendiendo sus productos de oro y plata con engarces de piedras preciosas a las damas citadinas de entonces, marcadas por una presunción sin límites; así, el narrador precisa:

Algo muy culminante fue la exhibición de alhajas. Las antiguas aristócratas, las godas, como las llamaba el pueblo, no dejaron piedra preciosa en el cofre de familia; pero la nueva aristocracia del dinero, las parvenues, o improvisadas por la Consolidación, las eclipsaron por el lujo de los vestidos y por la preciosidad de sus alhajas modernas engarzadas sobre oro. [...] Oímos decir en un grupo de la galería a don Bernardo el alhajero que el collar de perlas y prendas accesorias, también de perlas, que ostentaba la señora de un general llamaría la atención en la más fastuoso de las

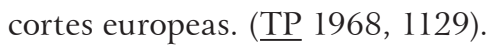

Esta opulencia limeña se verá luego ensombrecida de manera funesta por la Guerra del Pacífico cuyas causas, de alguna manera, se desprenden justamente de la codicia de ese esplendor. Para diversos historiadores e investigadores en el tema es casi un lugar común afirmar que "la principal causa de la Guerra fue la lucha por la apropiación de las riquezas naturales existentes en la provincia boliviana de Atacama y en la provincia peruana de Tarapacá. Para peruanos y bolivianos, en esa ambición participaron empresarios chilenos e ingleses y el propio gobierno chileno" (Cavieres y Cajías 135).

A su vez, Fonseca argumenta que: 
Al llegar la década de 1870, la situación empezó a cambiar tras el descubrimiento del valor del salitre. Chile, hasta entonces carente de grandes recursos, vio en dicho recurso un elemento necesario para su despegue económico, mientras que el Perú, agotadas sus reservas guaneras, también empezó a dar importancia a esos desérticos territorios sureños que parecían tener ahora la llave para prolongar su prosperidad. Bolivia, país mucho más andino que costero, solo se limitó a dar concesiones a empresarios chilenos y británicos para explotar el salitre. Estos inversionistas también incursionaron en las reservas salitreras peruanas que fueron estatizadas por el Estado peruano durante el gobierno de Pardo para paliar la grave crisis en la que se encontraba. Además, aunque Bolivia poseía importantes reservas de este mineral, más del 50\% del total de estas reservas se encontraba en la provincia peruana de Tarapacá. Chile [...] encontró el velado apoyo del capital británico ante las políticas económicas intervencionistas del Perú. El factor económico fue, sin duda, el más importante en el desencadenamiento del conflicto (Fonseca 63-4).

En esa línea reflexiva, Basadre piensa que "Perú y Bolivia pagaron caro, uno, su orgía política y financiera; el otro, su orgía política; ambos su imprevisión y desorden" (Basadre 2010, 245). Falta de visión y ausencia de orden fueron los rasgos que llevaron al error y al desconcierto, tan largos e inútiles de mencionar. Víctima de esa situación fue el pueblo peruano en su conjunto, amén del boliviano ${ }^{2}$, que tuvo que enfrentar una Guerra para la cual no estaba preparado. En ese contexto sobresalieron dos héroes que por excelencia representan lo mejor del Perú por haberse inmolado en defensa del territorio patrio. El almirante Miguel Grau, paladín del Combate de Angamos, acaecido el 8 de octubre de 1879, y el coronel Francisco Bolognesi, adalid de la Batalla de Arica, ocurrida el 7 de junio de 1880. Es al segundo a quien Palma dedicará líneas sentidas y de excepcional belleza.

2 Al respecto revisar el estudio del historiador boliviano Querejazu Calvo (1979). 


\section{"Francisco Bolognesi"}

"Francisco Bolognesi" es una tradición dividida en cuatro instancias y gira sobre el héroe peruano de Arica. El narrador que asume el relato está invadido por una inocultable emoción patria.

La literatura romántica, en particular, privilegia como tópicos, el amor, la muerte, la fe religiosa y la exaltación de la naturaleza. Así mismo, todas las acciones del relato predicen o anuncian un final trágico. Pero a pesar de ello, hay un inevitable anhelo de libertad plena en el ánimo de los protagonistas. La muerte, a veces, también conduce a esa ansiada libertad.

En la breve tradición "Francisco Bolognesi" curiosamente se aglomeran los rasgos esenciales del relato romántico. En el primer apartado, por ejemplo, se remite al lector a un hecho histórico acaecido en el entonces puerto peruano de Arica y que sirve de marco a la narración: "Eran las primeras horas de la mañana del sábado 5 de junio de 1880. Los rayos del tibio sol matinal caían sobre las paredes azules de una casita de modesta apariencia, situada en la falda del cerro de Arica y en dirección a la calle real del puerto" (TP 1968, 1152). El narrador prioriza fecha, lugar y clima. Va de lo general a lo particular, de lo externo a lo interno; ahora se anima a ingresar al interior de la casita.

Quien hubiera penetrado en la pieza principal, que mediría ocho metros de largo por seis de ancho, habría visto por todo humildísimo mueblaje una tosca mesa de pino, obra reciente del carpintero del Manco Capac; unos pocos sillones desvencijados, y una gran banca con pretensiones de sofá, trabajo del mismo escoplo y martillo. Al fondo, y cerca de una ventana, aún entornada, había una de esas ligeras camas de campaña que para nosotros, sibaritas 
de la ciudad, sería lecho de Procusto, más que mueble de reposo para el fatigado cuerpo. ( $\underline{\text { TP }} 1968,1152)$

El tibio sol externo alumbra una casita modesta compuesta de muebles incómodos y austeros. Nada en ese espacio anuncia confort ni lujo ni comodidad. Nada es nuevo. La estrategia del narrador lo obliga a presentar inmediatamente a su personaje protagónico:

Sentado junto a la mesa en el menos estropeado de los sillones, y esgrimiendo el lápiz sobre un plano que delante tenía, hallábase aquella mañana un anciano de marcial y expansivo semblante, de pera y bigote canos, mirada audaz y frente despejada. Vestía pantalón de paño grana con cordoncillo de oro, paletó azul con botones de metal, militarmente abrochado, y quepis con el distintivo de jefe que ejerce mando superior.

Era el coronel Francisco Bolognesi. (TP 1968, 1152).

Una visión de profunda soledad y abandono acompañan al anciano héroe. El protagonista está a más de mil kilómetros de la capital del país y se siente sin apoyo alguno. El destino lo ha colocado en tal circunstancia y la asume con dignidad y cierto aire sereno. La patria en ese instante se concentra en su valor. No hay dramatismo en sus acciones. Se trata de una heroicidad estoica. La pobreza de los muebles anuncia que Bolognesi y sus soldados están en desventaja plena frente a un rival superior en armas y hombres. La voz narrativa opta ahora por ahorrar mayores detalles del héroe, porque entiende que en tales circunstancias de adversidad el protagonista ha alcanzado la cima de su biografía:

No nos proponemos escribir la biografía del noble mártir de Arica; pues por bellas que sean las páginas de su existencia, la solemne majestad de su último día las empequeñece y vulgariza. En su 
vida de cuartel y de salón vemos solo al hombre que profesaba la religión del deber, al cumplido caballero, al soldado pundonoroso; pero sus postreros instantes nos deslumbran y admiran como las irradiaciones espléndidas de un sol que se hunde en la inmensidad del Océano. (TP 1968, 1152)

Para el narrador, el único sol que alumbra en plena adversidad en tierra peruana es Bolognesi. Todo lo que venga después no hará más que acrecentar su imagen de aguerrido anciano que se inmola por su linaje.

La segunda instancia de la tradición ahonda el dramatismo de tales circunstancias. No solo los diálogos así lo indican, sino el contenido de los mismos. Las fuerzas chilenas han sitiado el puerto de Arica y piden al coronel Bolognesi que se rinda. Para tal fin mandan a un emisario para abordar el asunto. El anciano militar recibe al comisionado chileno:

Un capitán avanzó algunos pasos hacia la mesa, y cuadrándose militarmente dijo:

- Mi coronel, ha llegado el parlamento del enemigo.

- Que pase -contestó Bolognesi, y se puso de pie.

El oficial salió, y pocos segundos después entraba en la sala un gallardo jefe chileno que vestía uniforme de artillero. Era el sargento mayor don Cruz Salvo.

- Mis respetos, señor coronel -dijo, inclinándose cortésmente el parlamentario.

- Gracias, señor mayor. Dígnese usted tomar asiento.

Salvo ocupó el sillón que le cedía Bolognesi, y éste se sentó en el extremo del sofá vecino. Hubo algunos segundos de silencio que al fin rompió el parlamentario diciendo:

- Señor coronel, una división de seis mil hombres se encuentra casi a tiro de cañón de la plaza...

- Lo sé -interrumpió con voz tranquila el jefe peruano-; aquí 
somos mil seiscientos hombres decididos a salvar el honor de nuestras armas.

- Permita usted, señor coronel -continuó Salvo-, que le observe que el honor militar no impone sacrificio sin fruto; que la superioridad numérica de los nuestros es como de cuatro contra uno; que las mismas ordenanzas militares justifican en su caso una capitulación, y que estoy autorizado para decirlo, en nombre del general en jefe del ejército de Chile, que esa capitulación se hará en condiciones que tanto honren al vencido como al vencedor. - Está bien, señor mayor -repuso Bolognesi sin alterar la impasibilidad de su acento-; pero estoy resuelto a quemar el último cartucho.

El parlamentario de Chile no pudo dominar su admiración por aquel soldado, encarnación del valor sereno, y que parecía fundido en el molde de los legendarios guerreros inmortalizados por el cantor de la Ilíada. Clavó en Bolognesi una mirada profunda, investigadora, como si dudase de que en esa alma de espartano temple cupiera resolución tan heroica. Bolognesi resistió con altivez la mirada del mayor Salvo, y este, levantándose, dijo:

- Lo siento, señor coronel. Mi misión ha terminado.

Bolognesi, acompañó hasta la puerta al parlamentario, y allí se cambiaron dos ceremoniosas cortesías. Al transponer el dintel volvió Salvo la cabeza, y dijo:

- Todavía hay tiempo para evitar una carnicería..., medítelo usted, coronel.

Un relámpago de cólera pasó por el espíritu del gobernador de la plaza, y con la nerviosa inflexión de voz del hombre que se cree ofendido de que lo consideren capaz de volverse atrás de lo una vez resuelto, contestó:

- Repita usted a su general que quemaré hasta el último cartucho. (TP 1968, 1152-53)

Cito en extenso porque de este diálogo dependerá el argumento tanto de la presente como de la siguiente tradición. En la 
tercera instancia del relato y luego de que Bolognesi reafirmara su posición de resistencia y combate frente a las fuerzas enemigas, el anciano coronel convoca a "una junta de guerra a los principales jefes que le estaban subordinados" para poner a consideración su punto de vista; cuál no sería su asombro cuando escuchó de boca de todos ellos la frase "iCombatiremos hasta morir!" (P 1968, 1153). Acá es donde la voz narrativa aprovecha para presentar al resto del séquito heroico peruano que resistió tenazmente en Arica: "el hidalgo Joaquín Inclán y el intrépido Justo Arias, dos viejos coroneles a quienes el hielo de los años no había alcanzado a enfriar el calor de la sangre; el tan caballeroso como infortunado Guillermo More; el circunspecto jefe [...] Mariano Bustamante, y el impetuoso comandante Ramón Zabala" (P 1968, 1153).

Los epítetos que selecciona Palma para ir nombrando a cada uno de los integrantes que defendieron el puerto sureño de Arica no son grandilocuentes ni exagerados, sino justos y equilibrados: hidalgo, intrépido, caballeroso, circunspecto e impetuoso. Pero aún la lista está incompleta. La voz narrativa necesita mencionar a los de menor rango, pero no por ello menos valerosos los dos hermanos Cornejo, Ricardo O'Donovan, Armando Blondel, casi un niño con la energía de un Alcides, y el denodado Alfonso Ugarte, gentil mancebo que en la hora del sacrificio y perdida toda esperanza de victoria, clavó el acicate en los flancos del fogoso corcel que montaba, precipitándose, caballo y caballero, desde la eminencia del Morro en la inmensidad del mar. iPara tan gran corazón, sepulcro tan inconmensurable! (19P 1968, 1154)

Esta suerte de apretada oda a los héroes de Arica se sustenta en los delicados términos usados en el relato, de ahí que el cuerpo de Alfonso Ugarte defendiendo el pabellón nacional solo puede ser recibido por el inconmensurable mar y aunque Armando 
Blondel era apenas un mozalbete, poseía la fortaleza de un dios mitológico griego. En medio de una lucha desigual, los hombres que se inmolan defendiendo a su patria solo pueden ser equiparados de manera superlativa con referentes míticos, más aún si se trataba de un auténtico sacrificio. El narrador contiene sus emociones y se inhibe de dar mayores detalles ante tanta heroicidad, y así lo explicita: "hecatombe que mi pluma rehúsa describir porque se reconoce impotente para pintar cuadro de tan indescriptible grandeza; todos a la vez que Francisco Bolognesi, cayeron cadáveres mirando de frente el pabellón de la patria y balbuceando en su última agonía el nombre querido del Perú" (TP 1968, 1154).

Estamos, como nunca, delante de un Palma irreconocible en tanto que ha creado una voz dolorosa y lacónica -tan distante a la que le conocemos por su imaginación alegre y su picardía sin fin- para narrar no la batalla abiertamente dispar, sino la asombrosa heroicidad de Bolognesi y su gente. El narrador se despoja de toda grandilocuencia épica porque sabe que frente a los cadáveres de los caídos en combate solo cabe el respeto y el silencio digno. Palma conoce los límites de la ficción y no pretende arriesgar absolutamente nada ante el luto nacional. Su pluma se suma así al duelo de la patria.

La tradición culmina con un cuarto apartado donde resume el accionar de los paladines peruanos y enuncia, a su vez, la resonancia internacional que tuvo la resistencia en Arica. El texto se cierra con un justo elogio al mártir de Arica, considerado desde entonces Padre del Ejército Peruano.

El coronel Bolognesi fue uno de esos hombres excepcionales, que llegan a una edad avanzada con el corazón siempre joven y capaz de apasionarse por todo lo noble, generoso y grande. Su gloriosa muerte es un ideal moral que vive y le sobrevivirá 
a través de los siglos, para alentarnos con el recuerdo de su abnegación heroica de patricio y de soldado.

Nosotros conocimos y tratamos a Bolognesi ya en la nebulosa tarde de su existencia; pero para nuestros hijos, para los hombres del mañana, que no alcanzaron la buena suerte de estrechar entre sus manos la encallecida y vigorosa diestra del valiente patriota, su nombre resonará con la pudorosa vibración del astro que se rompe en mil pedazos (TP 1968, 1154).

El narrador introduce una fuerte carga de lirismo a lo largo del relato y evidencia su justa admiración al héroe peruano subrayando su abnegación, su generosidad, su apasionamiento y, por su legado, su luminosidad.

\section{"Respuesta a una rectificación"}

Tan bello texto, difundido en diversos rincones del Continente, motivó una reacción chilena con el desagradable propósito de minimizar la figura de Bolognesi. En el texto "Respuesta a una rectificación," Palma -en tarea heroicamente solitaria- no hace más que enfrentarse a las fuerzas distorsionadoras araucanas en tanto que libra una particular batalla contra una versión antojadiza de los incidentes. En efecto, cinco años después de los hechos, es decir en 1885, el emisario chileno en Arica, José de la Cruz Salvo, niega que Bolognesi en la respuesta dada [...] hubiera habido la frase quemaré hasta el último cartucho. Muertos en el combate casi todos los jefes peruanos que asistieron a la junta de guerra, con excepción de los comandantes Roque Sáenz Peña, Marcelino Varela y Manuel C. de la Torre, apelo al testimonio de estos. El comandante Sáenz Peña la ha consignado en el brillante artículo que ha poco publicó en Buenos Aires. ( $\underline{\mathrm{TP}}$ 1968, 155) 
Para 1885 estos hechos estaban demasiado frescos como para olvidarlos. En este caso, el honor de la Patria pasaba, sin duda alguna, por defender la imagen y las palabras del héroe peruano, y así lo explicita el relato.

En cuanto al calificativo de vulgares que el señor coronel Salvo da a las palabras del inmortal batallador del Morro de Arica, permítame que le niegue competencia para tan decisivo fallo. Así como las obras del espíritu se juzgan solo con el espíritu, así los arranques del patriotismo se aprecian con el corazón y no con la cabeza: se sienten y no se discuten. [...] En un soldado de la educación de Bolognesi, nada más natural y espontáneo que su respuesta: quemaré hasta el último cartucho (TP 1968, 155).

Palma no podía, por consiguiente, dejar de esclarecer tal versión, pero necesitaba además de un argumento categórico e irrebatible, incluso que neutralizara y ridiculizara al propio Salvo. Para tal fin, el tradicionista acude a la historia misma de Chile y cita a Benjamín Vicuña Mackena, el historiador por excelencia de esa nación, y transcribe algunas líneas de la página 1125, tomo III, de su Historia de la Guerra del Pacífico, volumen impreso en 1881; es decir, un año después de los sucesos de Arica.

Llegado el parlamentario a la presencia del jefe de la plaza, la conferencia fue breve, digna y casi solemne de una y otra parte. Entablose el siguiente diálogo, que conservamos en el papel desde una época muy inmediata a su verificación, y que, por esto mismo, fielmente copiamos: - Lo oigo a usted, señor -dijo Bolognesi con voz completamente tranquila. -Señor -contestó Salvo-, el general en jefe del ejército de Chile, deseoso de evitar derramamiento inútil de sangre, después de vencido en Tacna el grueso del ejército aliado, me envía a pedir la rendición de esta plaza, cuyos recursos, en hombres, víveres y municiones, conoce. - Tengo deberes 
sagrados y los cumpliré quemando el último cartucho. - Entonces está cumplida mi misión -dijo el parlamentario levantándose, etc., etc. $(\underline{\text { TP }} 1968,155)$

Ya en tono irónico y fulminante, Palma culmina esta rectificación desautorizando y liquidando a su rival con este abrumador párrafo:

Ya verá el señor coronel Salvo que yo no he escrito un romance, ni dado pábulo a mi fecunda imaginación, como tiene la amabilidad de afirmarlo en su artículo rectificatorio. Si Bolognesi no pronunció la vulgaridad de quemaré el último cartucho en tal caso, ateniéndonos a Vicuña Mackenna y desdeñando otros informes y documentos oficiales, sería el mismo coronel Salvo, y no yo, el inventor de esa (para mí y para el sentimiento patriótico de los peruanos) bellísima y épica vulgaridad. (TP 1968, 1156)

Palma repara con atención en el artículo del coronel chileno José de la Cruz $\mathrm{Salvo}^{3}$ difundido en las páginas del diario El Mercurio de Valparaíso, porque lo considera difamatorio no solo contra un héroe patrio, sino contra la nación peruana en su conjunto. Acá la pluma de Palma se sacude del laconismo anterior y se nutre de una energía inusitada y de una fuerte dosis de mordacidad para zanjar de una vez por todas con una versión caprichosa sobre este importante y simbólico episodio para el imaginario nacional peruano. Salvo queda ridiculizado y humillado en la pluma de Palma.

3 La fama histórica de Salvo es funesta, tan así que la página oficial de Héroes y Personajes de la Guerra del Pacífico, patrocinada por las Fuerzas Armadas chilenas, se empeña en limpiar constantemente su deteriorada imagen, y en esos afanes acota "Su actuación en territorio peruano ha sido rodeada de leyendas negras de saqueos y abusos que no coinciden con los hechos históricos registrados y que parecen más bien parte de la propaganda antichilena de la época, propia de un estado beligerante." Ver <http://www.guerradelpacificol879.cl/ heroesypersonajes.html>. 


\section{"Un montonero"}

"Un montonero" es una breve tradición que tiene como protagonista al coronel Leoncio Prado, hijo del presidente de la República del Perú, general Mariano Ignacio Prado, quien en plena guerra con los chilenos se encontraba en viaje inútil por Europa tratando de comprar armamento. En este relato, Palma no solo se encarga de narrar el trágico final del joven oficial peruano, sino también de esclarecer y corregir las versiones caprichosas del coronel chileno Gorostiaga, participante de la Batalla de Huamachuco, acaecida en la sierra norte del Perú.

La tradición tiene entonces tres propósitos: a) relatar el comportamiento abusivo y sanguinario del ejército usurpador, b) mermar los honores otorgados al coronel chileno Gorostiaga después de la guerra y c) contar los momentos últimos del oficial peruano Leoncio Prado.

En efecto, en la primera instancia del relato, el narrador deja en claro que la batalla de resistencia realizada el 10 de julio de 1883 en Huamachuco fue el "último y heroico esfuerzo del patriotismo peruano contra el engreído vencedor en Chorrillos

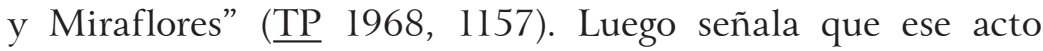
de entereza estuvo liderado por el general peruano Andrés Avelino Cáceres quien comandaba soldados que luchaban "con armamento desigual, escasos de municiones," carentes de bayonetas y que "emprendieron desesperado ataque sobre los dos mil chilenos de la aguerrida y bien provista división mandada por el coronel Gorostiaga" (TP 1968, 1157). De ahí que desde un inicio se subraye la condición logística dispar del ejército peruano frente a las fuerzas invasoras; pero a la vez, el narrador explícitamente elogia a las huestes peruanas compuesta, en este particular caso, por jóvenes campesinos ágrafos y quechuahablantes de la sierra norte del Perú que 
conformaron el ejército liderado por Cáceres en Huamachuco. Estos valerosos soldados, al igual que sus superiores, entregaron sus vidas por defender el honor nacional, y fueron víctimas acabada la batalla- del despiadado repase enemigo.

Palma ha elegido a un narrador frío para relatar las acciones deshumanizadas de los soldados chilenos, pero a su vez este mismo narrador especula sobre el posible cambio de rumbo de la historia si es que los peruanos hubieran luchado con paridad de armamento, tan así que señala que la fuerza chilena "llegó a encontrarse en situación aflictiva; y su derrota se habría consumado si, al estrecharse ambos combatientes, hubieran podido los peruanos oponer bayonetas a bayonetas. La hecatombe fue horrible: no hubo cuartel. Como en Miraflores, hubo repase de heridos" (푸 1968, 1157-58). La última oración sintetiza toda la brutalidad del adversario. El repase ${ }^{4}$ asesino de las bayonetas enemigas sobre los cuerpos laxos de los peruanos resume el espíritu sanguinario e inhumano del ejército chileno comandado por el coronel Gorostiaga.

En esta estrategia para intensificar los hechos, Palma otorga rasgo de investigador y cronista a su narrador, de ahí que el lector puede leer datos muy concretos "Los peruanos tuvieron mil doscientos muertos; esto es, el sesenta por ciento de sus

4 Ver la nota "El repase de heridos peruanos. Los crímenes de Chile y la violación de la Convención de Ginebra de 1864.” El texto va ilustrado por el cuadro "El repase", del pintor Ramón Muñiz, que se exhibe en el Museo del Real Felipe del Callao. Cf. <http://lamula.pe/2010/10/31/4/cavb>. Ahí se lee "El procedimiento fue practicado por la soldadesca de la República de Chile en cumplimiento de las órdenes de su comando. Consistía en ultimar a los heridos peruanos a la terminación de los combates. El asesinato era cometido con el cuchillo de la bayoneta o con el denominado corvo, puñal para degollar que utilizaba el ejército del país del sur. El repase es uno de los crímenes cometidos por Chile en la guerra que declaró al Perú el 5 de abril de 1879 . Constituyó una flagrante violación del artículo sexto de la Convención de Ginebra de 1864." 
fuerzas, y los chilenos ciento setenta bajas" (P 1968, 1158). Acá, el narrador contiene sus emociones y se limita a registrar los hechos. Incluso, asume el espíritu imparcial de un científico social cuando acota: "Chile tendría justicia en considerar la de Huamachuco como una de las más espléndidas victorias alcanzadas por su ejército, si el mismo coronel Gorostiaga no se hubiera encargado de rebajar los quilates del triunfo" ( $\underline{\mathrm{TP}}$ 1968, 1158).

Vale decir, Palma -que vivió aquellos años atroces y que legítimamente hubiera podido organizar hondos relatos dramáticos sobre los sangrientos episodios que los peruanos sufrieron durante la Guerra del Pacífico- opta por narradores cautos y sensatos. No obstante, en esta mezcla de sensaciones, el tradicionista siente el deber cívico y patriótico de reforzar la heroicidad de los caídos en batalla por medio de sus relatos, pero a su vez entiende que esa tarea implica serenidad de espíritu, cautela frente a las recientes y funestas consecuencias de la guerra y firmeza ética y estética en el proceso mismo de la producción textual para evitar el fácil efecto del lagrimeo. No hay en él afán alguno de revanchismo. Tampoco ánimo conciliador con el enemigo triunfador. Sí, en cambio, Palma muestra una clara intención por consolidar un espíritu unitario frente a la derrota, porque aun habiendo perdido el Perú la guerra, la nación necesita cerrar filas frente al desaliento generalizado en la población. Ante situaciones similares, Renan cree que la construcción de héroes en el imaginario nacional ayuda a edificar un pasado heroico sobre el cual se deberá reconstruir a la nación.

Palma está acorralado entre el dolor del Perú, el luto nacional y su profesionalismo como escritor literario. Su oficio deviene semejante al de un equilibrista que realiza malabares para no caerse en el mar de las emociones. Tal vez por ello, después 
de presentar el marco sangriento y desigual de la Batalla de Huamachuco, otorga a su narrador la patriótica misión de enfrentarse con energía al jefe de los chilenos

Gorostiaga, al ordenar el fusilamiento de Florencio Portugal y de otros jefes y oficiales que reclamaban las preeminencias de prisioneros, declaró que los vencidos eran montoneros y no soldados, y que, como a tales montoneros, los consideraba fuera de las leyes de la guerra.

Victoria de soldados disciplinados sobre montoneros es victoria barata y de la que no hay por qué enorgullecerse.

¿Los laureles de la gloria se hicieron acaso para ceñir la frente de un vulgar vencedor de montoneros?

Y sin embargo, esa matanza de cobardes montoneros mereció que Gorostiaga alcanzase los entorchados de general, ipremio honroso para el jefe que vence a tropas regulares, y no a turbas sin organización ni disciplina! ( $\underline{\text { TP } 1968,1158)}$

En el último párrafo citado, los signos de admiración cumplen una labor superlativa en tanto que arremeten no solo contra Gorostiaga, sino contra las altas esferas de las fuerzas armadas chilenas, porque es de perplejidad y de asombro constatar que toda una nación premie con los dorados galones de general a un sangriento vencedor de montoneros. La voz narrativa está desconcertada, pero le es necesario recobrar la mesura para señalar que el "jefe chileno, en su parte oficial, confiesa que combatió contra un verdadero cuerpo de ejército, que maniobraba con perfecta instrucción en la táctica, y que estaba sometido a la rigurosa disciplina de cuartel. Honrose allí el chileno vencedor honrando a los soldados vencidos" ( $\underline{\text { TP } 1968,}$ 1158). En estas líneas que extracta el parte de guerra enemigo, el vencedor honra al vencido, elogia sus virtudes castrenses y resalta la mano estratégica del general peruano Andrés Avelino Cáceres, pero Gorostiaga sabe que insistir en ello le acarrearía 
funestas consecuencias frente a la historia y a los hombres. De ahí que el narrador de la tradición ponga mayor peso en enjuiciar la crueldad chilena cuando anota

Pero Gorostiaga necesitaba disculpar ante el mundo su ferocidad felina, su insaciable sed de sangre; vengarse del terror que tuvo al ver sus batallones casi en derrota, y estampa la palabra montoneros, sin tener en cuenta que, al estamparla, empequeñece la valentía de los suyos y su propio merecimiento.

Ahora véase que solo los hombres de la legendaria Esparta sabían morir por su patria tan heroicamente como los montoneros de Huamachuco. (TP 1968, 1158)

La tradición "Un montonero" ha cumplido hasta acá sus dos primeros propósitos: a) enfatizar la crueldad de las tropas invasoras en tierras peruanas denunciando al mundo entero la violación de la Convención de Ginebra de 1864 por parte del ejército chileno y b) desacreditar el disparatado parte militar del coronel Gorostiaga que le ameritó el grado de general otorgado por su nación. Y como era de suponerse, en este apartado la voz narrativa subraya la valentía de los soldados peruanos al equipararlos a los denodados guerreros espartanos.

La última instancia de la tradición se aboca a relatar el final del joven coronel peruano Leoncio Prado, hijo del presidente de la República. Para tal fin, a pie de página, el propio Palma señala su fuente y la aclara: "Don Raimundo Valenzuela, jefe del ejército chileno, publicó en Santiago en 1885 un precioso librito sobre la campaña de Huamachuco [acaecida en 1883], el cual nos ha servido de fuente para este episodio" (TP 1968, 1158). Líneas después, el tradicionista encomia la objetividad del autor: "Esa justicia al mérito personal y al sentimiento patriótico de la noble víctima, hecha por pluma chilena, habla más alto de lo que nosotros pudiéramos hacerlo" (TP 1968, 1158). 
En este apartado, el relato cobra facciones dramáticas no solo por la abundancia de diálogos, sino por el contenido y el final trágico del héroe. En efecto, el oficial peruano Leoncio Prado fue uno de los heridos en Huamachuco y al ser detectado por un soldado chileno inmediatamente se identificó con su grado de coronel, pero con ánimo a su vez de que aquel lo matara con un disparo porque tenía "una pierna hecha astillas de un balazo" (TP 1968, 1158). El peruano le dijo: "Acércate [...], soy el coronel Leoncio Prado... Pon el cañón de tu rifle sobre mi frente y dispara" ( $\underline{\text { TP }}$ 1968, 1158). Es obvio que el soldado ocupante se sorprendió al ver a un oficial que no correspondía al prototipo indígena de la tropa peruana. Además, en este encuentro, el oficial le da una orden, no suplica por su vida ni implora piedad. Al verlo con los rasgos europeizantes de sus propios oficiales, algún efecto psicológico habrán causado su imagen y sus palabras sobre el soldado chileno, tan así que este solo optó por alejarse "en busca de sus compañeros" ( $\underline{\mathrm{TP}}$ 1968, 1158). Aunque no es nuestra intención ahondar sobre el tema de la raza en la conformación de los ejércitos enfrentados, es pertinente, sin embargo, recalcar que Andrés Avelino Cáceres -el jefe de Leoncio Prado en la batalla de Huamachuco- estuvo siempre apoyado por campesinos del Ande peruano durante la etapa de resistencia. Guzmán Palomino recuerda que los humildes comuneros de Tarmatambo "conformaron las guerrillas que unidas al ejército del centro triunfaron sobre los invasores chilenos en la gloriosa contraofensiva de 1882" (Guzmán Palomino 115).

El herido fue llevado al cuartel general de Huamachuco y es ahí donde Gorostiaga "dispuso que inmediatamente se pusiera

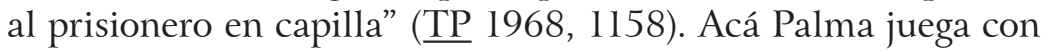
el doble significado de la palabra capilla en tanto que significa por un lado pequeña iglesia y por otro, estar en capilla ${ }^{5}$ alude en

5 El DRAE señala dos acepciones de la alocución verbal coloquial 'estar en 
el habla coloquial a la antesala de la muerte o en vísperas de alguna situación funesta. En la lógica del relato, el personaje estuvo en la capilla como prisionero y en capilla como reo antes de la muerte. Todo hacía suponer que Leoncio Prado correría la misma suerte que sus colegas anteriormente ejecutados sin juicio ni defensa alguna.

El episodio que continúa se resuelve en diálogos breves sin exageración alguna

Cuando vio que ya se presentaban para fusilarlo, pidió una taza de café, y al probarlo dijo:

- Hacía tiempo que no gustaba un café tan exquisito.

Y volviéndose al oficial que mandaba los tiradores chilenos, preguntó:

- ¿A qué hora emprenderé el viaje para el otro mundo?

- Cuestión de minutos -contestó el oficial.

- Pues bien: pido una gracia, y es que se me permita mandar el fuego.

- No hay inconveniente.

-¿Tienen capellán las fuerzas chilenas?

- No, señor.

-iPaciencia!... He hecho lo que he podido por mi patria, y moriré contento.

En seguida pidió que, en vez de dos tiradores, se colocaran cuatro, y que le apuntasen dos al corazón y dos a la cabeza. Acordada esta nueva gracia, dijo:

- Al concluir la taza de café se me harán los puntos; y al dar con la cuchara un golpe en el pocillo, se hará fuego.

capilla' y que a saber son 1. Dicho de un reo: Estar desde que se le notifica la sentencia de muerte hasta la ejecución, en cualquier pieza de la cárcel dispuesta como capilla.2. Dicho de otra persona: Hallarse en el trance de pasar una prueba o de conocer el resultado de algo que le preocupa. Cf. $<$ http://buscon.rae.es/draeI/SrvltConsulta? TIPO_BUS=3\&LEMA=capilla > 
Y continuó tomando reposadamente su café.

Ninguna idea triste nublaba su rostro. Veía sin zozobra agotarse el dulce líquido, sabiendo que en el último sorbo estaba la amargura.

Debió tranquilo el último trago, tocó con energía la cuchara en el pocillo, y cuatro balas diestramente dirigidas lo hicieron dormir el sueño eterno. ( $\underline{\text { TP } 1968,1158-59)}$

La ejecución arbitraria de Leoncio Prado determinada por Gorostiaga ahonda la visión sanguinaria del militar chileno que se contrasta de manera evidente con el buen ánimo con que el oficial peruano asume la muerte. En el parlamento del héroe rezuma estoicismo y cierta calma interior porque sabe que ha hecho todo lo posible por defender a su patria. Muere en paz y con la certeza de que su muerte no es inútil.

Se nos presenta a dos individuos en el campo de batalla que asumen la vida y la muerte de manera distinta. El chileno Gorostiaga fusila y mata en aras del ascenso militar y de los bienes materiales que se desprenden del nuevo rango; el peruano ha vivido para defender su terruño y muere con la consciencia de haber cumplido con su patria.

Palma entiende que sus tradiciones que evocan esta época, en especial, iban a ser leídas por generaciones posteriores de peruanos. Por ello, intensifica y fortalece la imagen de los héroes que entregaron sus vidas por la defensa de la patria. Las intensifica porque los caídos en la guerra encarnan la esencia misma de la nación. Son muertos que inyectan vida en el ánimo nacional. El proyecto liberal burgués necesita consolidarse en base a íconos unificadores y estables que deberán servir de paradigmas a los ciudadanos que forman la nación. El legado de Palma consiste no solo en narrar episodios trágicos o aclarar insistentemente las versiones antojadizas de 
los chilenos sobre la Guerra del Pacífico, sino en construir una literatura didáctica que cale hondo en el ánimo de los peruanos de todos los tiempos. La construcción de la nación implica, por consiguiente, no olvidar a los que la forjaron entregando su vida por ella.

\section{"La cajetilla de cigarros"}

En "La cajetilla de cigarros" se narra un episodio acaecido en Arica en junio de 1880. Deliberadamente analizo este relato al final para mostrar el estado anímico de Palma que difiere del que tuvo en las narraciones anteriores. La anécdota es simple y hasta jocosa, pero no por ello el narrador deja de intercalar cifras y opiniones que recalcan la gesta de las tropas peruanas, como por ejemplo esta:

Aquella mañana, la del 7 de junio de 1880, habían corrido raudales de sangre peruana en el legendario Morro de Arica. Francisco Bolognesi, el inmortal soldado, había sucumbido, cayendo en torno suyo 900 bravos de los 1,600 que formaban su cuerpo de ejército.

Se había batallado hasta quemar el último cartucho, y 6,500 soldados chilenos se adueñaron del Morro, sin más pérdida para ellos que la de 144 muertos y 337 heridos.

La lucha fue en la proporción de uno contra cuatro. La victoria no correspondió al esfuerzo heroico sino al número inflexiblemente abrumador. (TP 1968, 1156)

Desde un inicio, la tradición muestra la diferencia numérica de las tropas en el enfrentamiento de Arica que determinó al vencedor; sin embargo, hubo respuestas efectivas de las huestes peruanas que se destacan en el relato: 
En momentos de pronunciarse el desastre, un joven capitán peruano a quien acompañaban cuatro soldados, golpeó con la culata de su rifle el fulminante de una mina, produciéndose la explosión que mató a tres de los enemigos, dejando heridos o contusos a muchos más.

Disipada la espesa nube de polvo y humo, se encontraron el capitán García y sus cuatro valientes rodeados por un grupo de treinta chilenos al mando del teniente Luján. Toda resistencia era imposible, y los cinco peruanos fueron hechos prisioneros. (TP 1968, 1156)

Estos dos párrafos breves se constituyen como el nudo del relato; todo hace presuponer al lector que se desencadenará entonces un final trágico. Según esta lógica, los peruanos deberán ser fusilados, y así se hace saber:

En esos momentos se presentó un coronel quien, informado por Luján del estrago producido por la mina, dijo lacónicamente:

- Baje usted con esos hombres a la falda del Morro, y fusílelos.

Vencedores y vencidos emprendieron con lentitud el descenso de más de trescientos metros que los separaban de la llanura. ( $\underline{\mathrm{TP}}$ 1968, 1156)

Llama la atención el adverbio usado. El coronel chileno da la orden de fusilamiento lacónicamente. De alguna manera, ante las sanguinarias consecuencias de la batalla, vencedores y vencidos están asqueados de la muerte. La muerte rodea el escenario. Los muertos implícitamente invaden el Morro de Arica. La muerte enluta a los dos ejércitos. Mueren viejos y jóvenes en toda guerra. El oficial chileno, en una lectura atenta, se ha hartado de matar a un ejército numéricamente inferior y habla de manera concisa, quizás por ello no le queden ni fuerzas para expresarse con energía. Por esta razón, el adverbio anuncia algo insospechado al lector, un poco de azar acaso en medio 
de tanta desgracia. Y en ese angustiante vacío entre la vida y la muerte, la consciencia del narrador humaniza a los personajes y aprovecha para reflexionar sobre lo inútil y absurdo que es toda guerra. En este caso, Palma opta por un fino humor que disuelve toda tensión previa a la muerte:

Habrían caminado ya una cuadra cuando el capitán García se detuvo, y sin fanfarronería, con entera serenidad de espíritu, le preguntó al oficial chileno, que tenía aspecto de buen muchacho: - ¿Me permite usted, teniente, encender un cigarrillo?

- No hay inconveniente, capitán. Fume usted cuantos quiera hasta llegar a la falda.

García sacó del bolsillo de su talismán, nombre con que se bautizó, por entonces, a la levita de los oficiales, una cajetilla de cigarros de papel.

- ¿Fuma usted, teniente?

- Sí, capitán, y gracias -contestó el chileno aceptando el cigarrillo.

- Así como así -continuó García-, siendo este el último que he de fumar, hago a usted mi heredero de los doce o quince que aun quedan en la cajetilla, y fúmeselos en mi nombre.

Luján se sintió conmovido y aceptando el legado contestó:

- Muchas gracias. Es usted todo un valiente, y créame que me duele en el alma tener que cumplimentar el mandato de mi jefe. Y sin más, prosiguieron el descenso. (TP 1968, 1156-57)

Son dos jóvenes que dialogan en medio de una situación históricamente confusa. Ambos son víctimas del destino. El primero por estar a punto de convertirse en criminal, el segundo por morir a una edad inadecuada. Ambos aceptan con resignación su sino. Sin embargo, en el diálogo prevalece la amistad espontánea de los jóvenes. No hay rencor en sus corazones. Como dos amigos comparten la armonía del tabaco, hasta que el azar impone sus reglas, tal como el narrador lo advierte: 
Faltábales poco menos de cincuenta metros para llegar a la siniestra falda cuando, a una cuadra de altura, resonaron gritos dados por otro oficial chileno: - iEh! iLuján!; iTeniente Luján! ¡Párese, hombre! iEspéreme!

Luján mandó hacer alto a su tropa, y retrocedió para salir al encuentro del voceador.

¿Qué había sucedido? Que el coronel, calmada la primera impresión, reflexionó que su orden de fusilar prisioneros encarnaba mucho de injusticia y de ferocidad salvaje. Llamó a uno de sus subalternos y le mandó que corriese a detener a Luján.

- Dice el coronel -fueron las palabras del emisario al aproximársele su compañero-, que no fusiles a estos cholos y que los lleves al depósito de prisioneros.

- Me alegro -contestó Luján-, porque el capitancito me ha sido simpático, como que me ha hecho nada menos que su heredero.

Unido el teniente a los cautivos y a su tropa, dijo: - Le traigo a usted una buena noticia, capitán. Va usted, con sus cuatro hombres, al depósito de prisioneros. Ya no lo fusilo. (TP 1968, 1157)

Para obstaculizar a la muerte, la diosa fortuna se ha interpuesto entre Luján y García, dos jóvenes oficiales sudamericanos enfrentados por una guerra que ni uno ni otro originó. El mismo coronel que dio la orden inicialmente de manera lacónica sofrena sus pasiones porque considera absurdo seguir matando. Es el momento del sosiego, del respeto a los caídos en batalla; es el instante del silencio.

Pero a Palma no le es suficiente este relato de entraña pacifista; necesita poner su huella indeleble para alejarse de la atrocidad misma de toda guerra, por ello opta por la fina ironía, tan es así que pone en boca del oficial peruano este breve parlamento socarrón: “- Entonces, mi amigo -contestó el imperturbable capitán García-, se quedó usted sin herencia. Devuélvame mi cajetilla de cigarros" ( $\underline{\mathrm{TP}}$ 1968, 1157). 
Es sabido que los hombres fuman la pipa de la paz después de todo enfrentamiento; no obstante, una lectura literal de este relato sería acaso empobrecerlo. Los cigarrillos son propiedad del peruano. Bajo amenaza de muerte y ante su final irreversible, García dona su cajetilla a su par chileno. Acabado el episodio y perdonada su vida, el oficial peruano reclama que le devuelvan sus cigarrillos. En un contexto mayor y bajo la luz de los hechos históricos, Palma simbólicamente está exigiendo a través de su personaje que los chilenos devuelvan al Perú el territorio que usurparon. El tradicionista no es un sociólogo, es un artista que camufla con elegancia, humor y brillo un destello de mensajes como este, donde un soldado peruano se convierte en la voz de toda una nación.

A manera de balance final, coincidimos con el historiador Antonio Zapata cuando afirma que "emocionalmente los peruanos no nacimos en la independencia, sino en el conflicto de 1879" (Zapata 2011). Vale decir, la honda huella psicológica que ha ejercido la Guerra del Pacífico sobre la población peruana es de tal magnitud que hasta nuestros días pervive un sentimiento nacional que traspasa razas y clases, sentimiento confuso y unitario que reclama sanar múltiples heridas. Y Palma mejor que nadie lo sabía. Se trata de un hombre del XIX que sufrió los avatares de la guerra. En particular, a través de estas tradiciones -donde entremezcla ficción, historia y ensayo-, Palma expone un sentir nacional cuyos ideales son la unidad y la defensa del territorio patrio. La textura de estas tradiciones ensombrecen y un hálito de tristeza las invade. No obstante, los relatos son la respuesta de un artista que alienta al lector peruano a no sucumbir por el desastre nacional en el que se encuentra inmerso. Más aún, Palma propone acá paradigmas y diseña modelos de resistencia y heroicidad en las figuras de Francisco Bolognesi y Leoncio Prado. Texto y contexto se homologan en cuanto atmósfera funesta, más no en 
el ánimo del escritor quien exhorta a seguir en la larga batalla por el Perú.

Como es conocido, ${ }^{6}$ Palma fue víctima de las tropas chilenas cuando estas ocuparon Lima; su casa-como todas-fue vilmente saqueada y su biblioteca, impunemente quemada. Tratándose de un personaje público, los oficiales invasores dispusieron guardia permanente y ordenaron que su correspondencia fuera sometida a revisión continua. Son años duros (1881-1883) en que nuestro escritor subsiste básicamente de las colaboraciones literarias que hace al diario La Prensa, de Buenos Aires. Holguín Callo nos recuerda que "Después del Perú, seguramente no hay en América país donde más y mejor se conozca la obra de don Ricardo Palma que la República Argentina. Buen síntoma este de concederle importancia señera en la historia literaria de los pueblos hispanohablantes" (Holguín Callo 2001, 25l). Luego, el mismo autor añade que escritores y políticos de la zona del Río de la Plata (como Juana Manuela Gorriti, Roque Sáenz Peña, José Mármol, Hilario Ascásubi, Bartolomé Mitre, entre otros) "más de una vez le prodigaron al tradicionista peruano oportuno apoyo material o moral, v.gr. en los aciagos días de 1881-1883" (Holguín Callo 2001, 251). Por consiguiente, el escritor peruano afrontó infinidad de escollos para sobrevivir en medio del desastre nacional que la guerra originó. Por cierto que no fue el único. Todo el país vivió en zozobra durante ese período funesto de la historia peruana.

En ese sentido, para Palma recordar es negarse al olvido. Se recuerda no por rencor sino para valorar a la nación como ente real y vivo. En el fondo, en estos breves textos que aluden a la Guerra

6 Para aspectos biográficos puntuales revisar los libros de José Miguel Oviedo (1965); Angélica Palma (1937); o el libro colectivo patrocinado por la Sociedad Amigos de Palma (1934). 
del Pacífico no hay odio ni rencor, sino una llamada de atención a los peruanos de todos los tiempos para que en determinados momentos actúen como Francisco Bolognesi, Leoncio Prado, Alfonso Ugarte, Miguel Grau y los demás héroes que entregaron sus vidas en defensa de la patria. Se trata de un discurso de entraña nacionalista que persigue unificar al país en un contexto de desánimo generalizado. En estas tradiciones se evidencia un sentimiento que apuesta por la reconstrucción de la nación y que se condice con la reconstrucción real que impulsaron los sucesivos gobiernos después de la Guerra con Chile, en especial con el de Nicolás de Piérola y el de Eduardo López de Romaña. En este caso, la narrativa literaria acompaña el discurso oficial y el impulso renovador que se afana, como tarea inmediata, por rehacer el país desde los escombros que dejó la trágica contienda.

Así mismo, la recuperación de la memoria tiene una dinámica generacional ${ }^{7}$ muy clara, en tanto que escritores coetáneos a Palma, como M. González Prada, R. Rojas y Cañas, A. Gamarra, Manuel A. Fuentes, entre otros, abordaron el tema desde su particular visión. De todos ellos, los breves textos de Palma son los más ecuánimes frente a los encontrados análisis que se hicieron después de la conflagración. No obstante, al recordar los hechos, el escritor limeño toma partido por la nación peruana, por su integridad territorial y por su población víctima de los atropellos del ejército usurpador, pero lo hace sin caer en las tentaciones del naturalismo. En ese sentido, su visión calza con la definición de Anderson cuando afirma que la nación es una "comunidad política imaginada como inherentemente limitada y soberana" (Anderson 23).

7 Cf. Guerra con Chile (1879) de Manuel Atanasio Fuentes; La Guerra del Pacífico (1880) de Ramón Rojas y Cañas; los artículos de Abelardo Gamarra escritos desde 1883 en las páginas del diario que fundó y dirigió, Integridad, y en cuyas páginas apoyó la causa de Andrés Avelino Cáceres; o Pájinas libres[sic] (1894) de Manuel González Prada. 
De otro lado, como ciudadano, Palma supo decir su amargura con firmeza y mostrar su desazón frente a la invasión chilena, tal como se desprende de las siguientes líneas que le dirige a Nicolás de Piérola, quien por entonces era el Jefe Supremo del Perú; así, el tradicionista, el 9 de abril de 1881, escribe: "Para nosotros el deber no es el Dios éxito: el deber es la lucha. No me halago con la idea de paz" (R. Palma 1979, 22). Meses después y siempre desde el ámbito privado, le vuelve a escribir al mismo destinatario el 27 de junio de 1881: "No son armas ni municiones lo que necesitamos para escarmentar al enemigo chileno y vengar los pasados desastres. Es patriotismo y unión" (R. Palma 1979, 52). Este sinsabor alcanzó grado superlativo cuando Ricardo Palma escribe y dirige su legítima protesta a la oficialidad chilena en Lima. Incluso su hijo Clemente ha escrito de manera detallada al respecto:

A los pocos días de ocupada la capital del Perú por el ejército de Chile, la Biblioteca de Lima fue destinada a alojamiento de un batallón, y sus libros, considerados como botín de guerra, trasladados en parte a Chile y en parte entregados a la soldadesca para que los vendiera en las bodegas como papel para envolver mercaderías. Ricardo Palma, con la honda pena e indignación que le causara este salvaje agravio a la cultura, escribió una enérgica y violenta protesta al jefe de la plaza [...]. La autoridad chilena procedió inmediatamente a apresar al [...] autor de esta protesta. Recuerdo la mañana en que mi madre y yo fuimos a visitar al preso en una habitación del corredor alto de la Biblioteca. En la tarde de ese día fue conducido al pontón Valdivia, de donde debía ser trasladado al barco que debería llevarle prisionero a Chile. Felizmente, reconocida su alta personalidad literaria, [...] se detuvo esta nueva expatriación. (C. Palma 211)

Por estas consideraciones, Palma no dudó en asumir, después de la guerra, la dirección de la Biblioteca Nacional, literalmente 
saqueada por las tropas enemigas. Sus biógrafos ${ }^{8}$ han señalado su capacidad de restaurador de la primera casa lectora del Perú, ganándose por ello el epíteto del "Bibliotecario Mendigo." Esta labor lo obligó, entre otras funciones y roles, a denunciar insistentemente el abuso chileno frente al patrimonio bibliográfico peruano, tal como se aprecia en estas líneas de la tradición "Sobre el Quijote en América":

Cuando la destrucción de la Biblioteca de Lima por los chilenos, en 1881, desapareció el ejemplar que poseía el Perú, y que perteneció a la librería de los jesuitas, la cual sirvió de base a la Nacional, fundada por el general San Martín en 1821. El ejemplar no llegó a la Biblioteca de Santiago, ni hay noticia de que lo hubiera adquirido bibliófilo alguno de Europa o América, pues bien se sabe que los hombres dominados por la manía de acaparar libros, jamás guardan secreto sobre los ejemplares raros que adquieren, y gozan con echar la nueva a los cuatro vientos. Como muchas de las obras fueron vendidas a vil precio por la soldadesca en los bodegones, utilizándose el papel para envoltorios de sal molida o de pimienta, no es aventurado recelar que tan indigna suerte haya cabido al curiosísimo librito. ( $\underline{\text { TP } 1968,251)}$

Hasta Rubén Darío, que había escrito elogiosos versos a la victoria chilena, avergonzado anotó lo que el propio Palma le contase en la furtiva visita que le hiciese el nicaragüense en Lima en 1890: "i[La Biblioteca Nacional fue] rica antes de que la destrozaran los chilenos! Cuando la ocupación, entraban los soldados ebrios a robarse los libros. [...] Me narraba atrocidades. Me dijo todo lo que había sufrido en los tiempos terribles" (Darío xv).

Tal como se aprecia, Palma percibe los libros como hijos legítimos de una nación; la pérdida de uno de ellos no solo empobrece

8 Ver José Miguel Oviedo (1965) y Holguín Callo (2001). 
culturalmente al país poseedor del libro, sino que también disminuye espiritualmente a la nación que la hurta. Aún dicho tema sigue siendo harto sensible en la relación bilateral entre Perú y Chile, tal como se aprecia en las declaraciones emitidas por el historiador Ramón Mujica Pinilla, ${ }^{9}$ actual director de la Biblioteca Nacional, quien en voz alta declara: "Uno se pregunta qué hacen los más de 500 legajos del Santo Oficio de la Inquisición en Santiago de Chile. La Inquisición estaba en Lima no en Chile. Esos serían parte de los documentos que debemos solicitar para que retornen al Perú" (Escribano 29).

\section{Balance}

A manera de balance final diremos que la Guerra del Pacífico originó una profunda crisis nacional en el Perú. Crisis que invadió todas las instancias organizativas y anímicas de la nación. El dolor colectivo y el desasosiego total en el ánimo de la población son la consecuencia de este enfrentamiento que como ningún otro episodio del XIX caló hondo entre los peruanos de todas las clases, razas y origen. En ese escenario, Ricardo Palma plantea reflexionar en medio del dolor. En su imaginario, el escritor cree inconveniente y poco fructífero exacerbar ánimos porque las heridas de la guerra, por entonces, seguían abiertas y sangrantes. Lo que propone Palma es una suerte de unidad nacional $^{10}$ en medio del dolor; unidad que implica guardar

9 Ver la entrevista que le realiza Pedro Escribano en el diario limeño La República, el 27 de enero de 2012.

10 A diferencia de Manuel González Prada, Palma apuesta por una nación unida luego del desastre de la Guerra. Para Zapata, por ejemplo, González Prada integró "la generación radical que siguió a la guerra con Chile, descubriendo la rebeldía y el indigenismo. Por primera vez se formuló un discurso encendidamente nacionalista que paralelamente desarrollaba un juicio negativo de la clase alta criolla. Se la juzgaba incapaz de construir una nación moderna, debido a su egoísmo inveterado, que gozaba la riqueza 
respetuoso silencio por las vidas perdidas, pero sin olvidar que el enemigo ha mutilado territorial y anímicamente a la nación.

Las heridas de la guerra unifican al país, porque cada quien ha perdido algo o a alguien en esta escaramuza: padres e hijos muertos en batalla, mujeres de todas las edades deshonradas vilmente, amén de casas y pueblos saqueados, destruidos y quemados. Todo lo que constituye una nación está herido; las razas, las lenguas, el territorio, la religión, las diversas comunidades y hasta la geografía misma parece acusar enfermedad. Palma coincide con lo que sostenía Renan: "una nación es un alma, un principio espiritual” (Renan 82). Y esa energía anímica está literalmente resentida y afectada. En ese contexto, y parafraseando a Renan, el Perú se unifica por su derrota y paradójicamente cada derrota consolida al Perú, porque el Perú sí es una nación que existe por sí misma. Al respecto, el pensador francés sostiene que:

La nación, como el individuo, es la consecuencia de un largo pasado de esfuerzos, de sacrificios y desvelos. El culto a los antepasados es el más legítimo de todos; los antepasados nos han hecho lo que somos. Un pasado heroico, grandes hombres, la gloria [...]; he aquí el capital social sobre el cual se asienta una idea nacional. Tener glorias comunes en el pasado, una voluntad común en el presente; haber hecho grandes cosas juntos, querer hacerlas todavía, he aquí las condiciones esenciales para ser un pueblo. Se ama en proporción a los sacrificios soportados, a los males sufridos. (Renan 82-3)

Este es el sentimiento que irradian las tradiciones palmistas sobre la Guerra con Chile. El Perú tiene héroes que no se

nacional marginando a las mayorías. La derrota en la guerra estimulaba ese planteamiento, porque al buscarse culpables internos, González Prada tenía la respuesta: los ricos encaramados por el guano al control del Estado y la sociedad" (Zapata 2012, 5). 
rindieron, que lucharon hasta quemar el último cartucho, hombres que supieron enfrentar con honor e hidalguía la defensa de la patria, aunque hubieran perdido y hubieran muerto en sus afanes. No son muertes inútiles, parecen decirnos los relatos analizados en este trabajo. El Perú se consolida como nación a pesar de la humillante derrota. Este es el legado último que Palma deja a sus lectores.

\section{BIBLIOGRAFÍA}

Anderson, Benedict. Comunidades imaginadas. Reflexiones sobre el origen y la difusión del nacionalismo. México: Fondo de Cultura Económica, 1993. Print.

Basadre, Jorge. Historia de la República del Perú. 13 vols. Lima: Editorial Universitaria, 1968-1969. Print.

- - Perú independiente. 1948. Lima: Editora El Comercio, 2010. Print.

Cavieres, Eduardo y Fernando Cajías (Eds.) Chile-Bolivia, Bolivia-Chile: 1820-1930. Valparaíso: Ediciones Universitarias de Valparaíso, 2008. Print.

Chávez Rodríguez. Juan Manuel. La idea de nación en LA GUERRA del Pacífico (Lima, 1880), de Ramón Rojas y Cañas. Lima: Universidad Nacional Mayor de San Marcos. Facultad de Letras y Ciencias Humanas. Tesis de Licenciatura, 2008.

Cornejo Polar, Antonio. La formación de la tradición literaria en el Perú. Lima: Cep, 1989. Print.

- -. "La literatura hispanoamericana del siglo XIX: Continuidad y ruptura (Hipótesis a partir del caso andino)." Esplendores y 
miserias del siglo XIX. Cultura y Sociedad en América Latina. Eds. Beatriz González Stephan; Javier Lasarte, Graciela Montaldo y María Julia Daroqui. Caracas: Monte Ávila Editores, 1995. 11-23. Print.

Cosamalón Aguilar, Jesús. "El lado oscuro de la luna. Un ensayo acerca de los sectores populares limeños en el siglo XIX." La experiencia burguesa en el Perú, 1840-1940. Ed. Carmen Mc Evoy. Madrid-Frankfurt: Iberoamericana-Vervuert, 2004. 151-92. Print.

Dager Alva, Joseph. Historiografía y Nación en el Perú del siglo XIX. Lima: Fondo Editorial de la Pontificia Universidad Católica del Perú, 2009. Print.

Darío, Rubén. Cuentos completos. La Habana: Editorial Arte y Literatura, 1990. Print.

- - -. "Fotograbado." Palma, Ricardo. Tradiciones Peruanas. Barcelona: Montaner y Simón, 1893. xiv-xviii. Print.

Díaz Falconí, Julio. Cronología de las Tradiciones Peruanas. Lima: Universidad Ricardo Palma, 2005. Print.

Diccionario de la Real Academia Española (DRAE 2011) $<\underline{\text { http://www.rae.es }}>$.

"El repase de heridos peruanos. Los crímenes de Chile y la violación de la Convención de Ginebra de 1864." (2010). 20 Dic 2011 < http://lamula.pe/2010/10/31/4/cavb $>$.

Escribano, Pedro. "Tenemos que llegar a los responsables. [Entrevista con Ramón Mujica Pinilla]." La República. Lima: 27 Enero 2012. 29. Print. 
Espinoza, Antonio. "Moldeando a los ciudadanos del mañana: el proyecto educativo disciplinador en Lima, entre 1850 y 1900." Más allá de la dominación y la resistencia. Estudios de historia peruana, siglos XVI-XX. Eds. Paulo Drinot y Leo Garofalo. Lima: IEP, 2005. 238-59. Print.

Fonseca Ariza, Juan. Historia del Perú. Un Estado en formación (1827-1883). Lima: Empresa Editora El Comercio, 2011. Print. Fuentes, Manuel Atanasio. Guerra con Chile. Lima: Litografía de P.T. Rinaldi, 1879. Print.

González Prada, Manuel. Pájinas libres. 1894. Lima: Ediciones Copé, 1985. Vol. 1 de Obras completas. Print.

Guzmán Palomino, Luis (Ed.) La primera memoria de Cáceres y otros documentos relativos a la Campaña de la Breña. Lima: Universidad Alas Peruanas, 2010. Print.

Héroes y personajes de la Guerra del Pacífico. (2009). 15 Dic 2011 $<$ http://www.guerradelpacificol879.cl/heroesypersonajes. $\underline{\text { html }}>$.

Holguín Callo, Oswaldo. Páginas sobre Ricardo Palma. Lima: Universidad Ricardo Palma, 2001. Print.

Klarén, Peter F. Nación y sociedad en la historia del Perú. Lima: IEP, 2004. Print.

McEvoy, Carmen (Ed.) La experiencia burguesa en el Perú, 18401940. Madrid-Frankfurt: Iberoamericana-Vervuert, 2004. Print.

Murazzo, Alex. "La prosperidad falaz." Documentos históricos: Ciencias Sociales y Actualidad. (2007). 2 Enero 2012: < http:// sucesoshistoricos.blogspot.com/2007/07/la-prosperidad-falaz. $\underline{\mathrm{html}}>$. 
Novoa, Mauricio. "La 'civitas' inconclusa: Ideas sobre la soberanía de la nación en 1860-1900." La experiencia burguesa en el Perú, 1840-1940. Ed. Carmen Mc Evoy. Madrid-Frankfurt: Iberoamericana-Vervuert, 2004. 267-84. Print.

Oviedo, José Miguel. Genio y Figura de Ricardo Palma. Buenos Aires: Eudeba, 1965. Print.

Palma, Angélica. Ricardo Palma, el tradicionista. 1933. Lima: Editorial Castrillón Silva, 1937. Print.

Palma, Clemente. "En torno al centenario de Ricardo Palma." Ricardo Palma, 1833-1933. Ed. Sociedad Amigos de Palma. Lima: Compañía de Impresiones y Publicidad, 1934. 207-15. Print.

Palma, Ricardo. Tradiciones Peruanas Completas. Con siete extensos apéndices y una selección de cartas del autor. 6a. ed. Ed. Edith Palma. Madrid: Aguilar, 1968. Print.

- - . Cartas a Piérola (Sobre la ocupación chilena de Lima). 2a. ed. Ed. Rubén Vargas Ugarte, S.J. Lima: Editorial Milla Batres, 1979. Print.

Querejazu Calvo, Roberto. Guano, salitre, sangre. Historia de la Guerra del Pacífico. La Paz: Editorial Los Amigos del Libro, 1979. Print.

Renan, Ernest. ¿Qué es una nación? / Cartas a Strauss. 1882. Ed. Andrés Blas Guerrero. Madrid: Alianza Editorial, 1987.

Rojas y Cañas, Ramón. La Guerra del Pacífico. Lima: Imprenta del Universo de Prince y Buxó, 1880. Print. 
Sánchez, Luis Alberto. Don Ricardo Palma y Lima. 1926. Lima: Municipalidad de Lima, 1989. Print.

Sociedad Amigos de Palma (Eds.). Ricardo Palma, 1833-1933. Lima: Compañía de Impresiones y Publicidad, 1934. Print.

Vicuña Mackenna, Benjamín. Guerra del Pacífico. 4 vols. Santiago de Chile: Rafael Jover Editor, 1880. Print.

Zapata, Antonio. "Miguel Grau y sus biógrafos" La República. Lima: 30 Nov 2011. 7. Print.

- - - "La Generación de González Prada." La República. Lima: 11 Enero 2012. 5. Print. 